\title{
Perception of M.B.B.S. Students about Different Teaching Aids Used in Physiology Lectures in Karwar Institute of Medical Sciences, Karwar: A Questionnaire Based Study
}

\author{
Rupali Vijaykumar Waghmare ${ }^{1}$, Muniyappanavar N.S. ${ }^{2}$ \\ ${ }^{1}$ Assistant Professor, ${ }^{2}$ Professor, Department of Physiology, Karwar Institute of Medical Sciences, Karwar
}

\begin{abstract}
Introduction: Initially first year course duration was one and half year. It was used to study these subjects for one \& half year, but since 2005-2006, first year duration is reduced to one year; but the syllabus for all three subjects is not altered. The first year curriculum starts in the month of August/September in RGUHS while university examination is held in month of June/July. Actually considering government holidays \& other things, the actual working days are almost 11 months. The first year MBBS medical students who have admitted in medical college, they have to study three subjects; Anatomy, Physiology \& Biochemistry in I st \& IInd Semister. In the present study we focused on finding best teaching aids of class room teaching for making students to understand Physiology better. So if we know learning styles of students, teachers can adopt method of teaching accordingly to improve the academic performance of the students and to make learning more interesting and effective.
\end{abstract}

Material and Method: The present study was undertaken in the Karwar Institute of Medical sciences, Karwar. 150 I $^{\text {st }}$ year MBBS (II ${ }^{\text {nd }}$ Term) students \& 150 II $^{\text {nd }}$ year (III term) MBBS students were included in the study. A questionnaire was prepared having 21 items, the first part of questionnaire included demographic and educational details, while second part was covering the different aspects of teaching aids in the form of opinion by medical students.

Results: $85 \%$ students were felt that PPT should always combined with other teaching aid and $52 \%$ students were not affected by transition from PPT to blackboard teaching due to any external cause.

Conclusion: Blackboard + Power point is best teaching aid to understand Physiology better. This result may be due to the fact that deficiency of one teaching aid is compensated by other.

Keywords: Physiology, medical students, power point, teaching.

\section{Introduction}

The first year MBBS medical students who have admitted in medical college, they have to study three subjects; Anatomy, Physiology \& Biochemistry in Ist

\section{Corresponding Author:}

Dr. Muniyappanavar N.S.

Professor, Department of Physiology, Karwar Institute of Medical Sciences, Karwar
\& IInd Semister. Initially first year course duration was one and half year. It was used to study these subjects for one \& half year, but since 2005-2006, first year duration is reduced to one year; but the syllabus for all three subjects is not altered. The first year curriculum starts in the month of August/September in RGUHS while university examination is held in month of June/ July. Actually considering government holidays \& other things, the actual working days are almost 11 months. Within this duration, all three departments; Anatomy, Physiology, Biochemistry completes their subject wise curriculum effectively with a team of teaching staff 
members using different teaching method. For first year MBBS medical students initial one to two months are required for adjustment as there is drastic change from school environment to professional college, very well supported \& pampered circumstances to very independent circumstances. So overall they are getting 10 months for self study, so students are focusing on the easy ways to clear university examination, by accepting the concise books which is dampening the depth of subject knowledge. In the present study we focused on finding best teaching aids of class room teaching for making students to understand Physiology better. So if we know learning styles of students, teachers can adopt method of teaching accordingly to improve the academic performance of the students and to make learning more interesting and effective.

Aim: To find out best teaching aids of class-room teaching for making students to understand Physiology better.

\section{Objectives:}

(i) Understanding best teaching aids of Physiology teaching in lecture gallery.

(ii) To find out the best teaching aids considering following aspects; to understand the topic well, best perception of text, diagrams, flow charts, to take down notes, to cope up with speed of teacher, grasping the content of topic, method helpful to stress important points, better summarization, showing different clinical conditions and further stimulation to read from students perspective.

\section{Materials}

The present study was undertaken in the Karwar Institute of Medical sciences, Karwar. $150 \mathrm{I}^{\text {st }}$ year MBBS (II ${ }^{\text {nd }}$ Term) students \& 150 II $^{\text {nd }}$ year (III term) MBBS students were included in the study. Questionnaire was administered in the month of March to April 2019 after getting ethical committee approval.

Inclusion criteria: $150 \mathrm{I}^{\text {st }}$ year MBBS (II ${ }^{\text {nd }}$ Term) students \& $150 \mathrm{II}^{\text {nd }}$ year (III term) MBBS students were included in the study.

Exclusion criteria: Students who were absent on particular day, students who did not respond to any question.

\section{Methodology}

A questionnaire was prepared having 21 items, the first part of questionnaire included demographic and educational details, while second part was covering the different aspects of teaching aids in the form of opinion by medical students. The questionnaire was closed ended one with a few open ended questions. The same was validated. The ethical principles were also adhered too. Students were summarized about objectives of the present study and assured confidentiality. Students were encouraged to furnish unbiased independent opinion regarding the best teaching aid they preferred irrespective of the teachers and topic. Teaching aids used in the study were blackboard, Microsoft Power Point presentation and blackboard with Power Point presentation. The questionnaire was assimilated and analyzed to derive the results.

\section{Questionnaire asked based on the above teaching aids were:}

- $\quad$ to understand the topic well,

- best perception of text, diagrams, flow charts,

- to take down notes,

- to cope up with speed of teacher,

- grasping the content of topic,

- method helpful to stress important points,

- better summarization,

- $\quad$ showing different clinical conditions, and

- Further stimulation to read from student's perspective.

Data Analysis: The response was analyzed using Microsoft Power Point Excel for data entry, calculating frequencies and percentages and making graphs \& pie charts.

\section{Result}

In the present study, total 297 students participated, out of that $144(48 \%)$ were females \& $153(52 \%)$ were males. 209(70\%) students had schooled in English medium, $84(29 \%)$ in Kannada medium \& $4(1 \%)$ in Hindi medium. $175(59 \%)$ students were from private school while 122 (41\%) from government school \& the teaching aid predominantly used in the school was blackboard $150(51 \%)$ followed by multimedia 75(25\%), PPT + Blackboard 46 (16\%) \& PPT 26(9\%). 
242(81\%) Students were preferred Blackboard+ powerpoint presentation as their first choice teaching aid for Physiology Subject, followed by blackboard $40(13 \%) \&$ power point presentation $15(5 \%) .210(71 \%)$ students were preferred blackboard + powerpoint presentation for didactic lectures. Even ability to think with understanding the topic better $128(43 \%)$ \& well organization of topic $134(45 \%)$, to grasp the contents of the topic 128 (48\%), for better summarization 112(38\%) blackboard + powerpoint presentation, were opted by students respectively.

But for better inclusion of context 110(37\%), visual quality of text \& figures $172(58 \%)$, better perception of diagrams, flow charts $176(59 \%)$, for better understanding of clinical conditions (edema, anemia, endocrine disorders.....) 144(48\%) students respectively were preferred powerpoint presentation only. $115(39 \%)$ students who were not interested in taking notes during class were opted powerpoint presentation best for listening \& understanding the topic followed by blackboard teaching 99(33\%) students. $172(58 \%)$ students who were interested in taking notes during class, were found blackboard as best teaching aid . Blackboard preferred by 169 (57\%) students to cope with teaching speed of the teacher, stresses upon the relevant \& important information 114 (38\%), stimulates further reading $135(45 \%)$, for small group discussion $(<30) 202(68 \%) .252(85 \%)$ students were felt that PPT should always combined with other teaching aid \& $153(52 \%)$ students were not affected by transition from PPT to blackboard teaching due to any external cause.

\section{In our study one open ended question was added to the questionnaire:}

"Mention THREE important ways by which you think the use of blackboard as traditional teaching method can be improved?"

\section{The major points suggested by students were:}

1. PPT or other teaching aid should always combine with Blackboard teaching. The reasons mentioned were poor illumination, handwriting, drawings/ diagrams, dirty blackboard, but with PPT visual quality of text, figures, perception of diagrams, flow charts, understanding of clinical conditions were better compared to blackboard.

2. Use of different colored chalks for diagrams \& for stressing important points (key words) for particular topic.
3. Only blackboard or only PPT teaching was found monotonous. With only PPT, interaction between student \& teacher was less, also to cope up with speed of teacher \& taking notes were difficult task for students. But combination of both, increases attention span,

4. Important points should be written on the blackboard so that students will remember key points, will get the flow of topic.

\section{Discussion}

Anatomy, Physiology, Biochemistry are three basic subjects for $I^{\text {st }}$ year MBBS course. Physiology is the study of functions, their mechanisms and regulation in all living organisms. Physiology is the mother branch of medicine. Knowledge in Physiology is fundamental in understanding all other subjects in medicine. Medical teachers have conventionally using different teaching aids for teaching different subjects. Lectures can be traced as far back as Greeks of the fifth century BC, up till now lectures are the most common form of teaching ${ }^{1}$. Previously blackboard \& slide projector are the main teaching aids. Now a day's different audiovisual aids are introduced as teaching aids among them Power Point presentation, use of animated clips, videos are in use. Attempts had been made previously to search best teaching aids in lecture gallery for teaching medical students. In the present study attempts had been made to find out learning styles of the students, accordingly teachers can adopt changes in method of teaching $\&$ able to improve academic performance.

In the present study, 242(81\%) Students were preferred blackboard+ powerpoint presentation as their first choice teaching aid for Physiology Subject, followed by blackboard $40(13 \%) \&$ power point presentation $15(5 \%)$.

$210(71 \%)$ students were preferred blackboard + powerpoint presentation for didactic lectures. Even ability to think with understanding the topic better $128(43 \%) \&$ well organization of topic $134(45 \%)$, to grasp the contents of the topic $128(48 \%)$, for better summarization $112(38 \%)$ blackboard +powerpoint presentation, were opted by students respectively.

Rajani Shantthakumari Nagothi, Yogananad Reddy Indla et al found preference for blackboard with PPT for better understanding of Physiology ${ }^{2}$. Study done by Lalit Mohan, Ravi Shankar P, students preferred a 
combination of audiovisual aids during didactic lectures. Even perception of diagrams, flow-charts, note taking, listening \& understanding a particular topic was best accepted with $\mathrm{PPT}^{3}$. The study done by Priyadarshni K.S., H.V. Shetty, Reena R. for Biochemistry theory classes, PPT in combination with blackboard was found most helpful teaching aid to understand, remember $\&$ reproduce the subject ${ }^{4}$. Chaudhary $\mathrm{R}$ in his study, students pointed out drawback in Black Board teaching, is that it takes time to draw a labeled diagram on the board and during that time teacher's eye contact with the students is interrupted and majority of the students (67.1\%) favored the combination of teaching aid ${ }^{5}$. Thirunavukkarasu et al had used two different teaching aids for teaching \& observed marks secured by 60 students. They found that medical undergraduates in pathology subject had a more favorable response towards Power Point presentation than blackboard for better inclusion of content $\&$ diagrams ${ }^{6}$. S.N. Baxi et al in their study showed that an equal number of students preferred blackboard based and multimedia based lectures? Roopakulakarni et al concluded that audio-visual aids enhance effectiveness of blackboard teaching, $56.1 \%$ of students prefer blackboard teaching \& $42.2 \%$ of students prefer multimedia presentations ${ }^{8}$. Garg et al showed that $81 \%$ of the students wanted teacher to make use of audiovisuals aids during pharmacology lectures ${ }^{9}$. Sujata Biswas et al studied that both Power Point \& chalkboardshould be used simultaneously ${ }^{10}$.

Implications of the Study: The present study we focused on finding best teaching aids of class room teaching for making students to understand Physiology better. So if we will know learning styles of students, teachers can adopt method of teaching accordingly to improve the academic performance of the students and to make learning more interesting and effective.

Acknowledgement: Authors sincerely thanks to the Dean, Director \& HOD, department of Physiology, KRIMS Karwar for their continuous encouragement \& support. Authors thanks to II \& III term MBBS students for their active participation.

Ethical Clearance: Taken from Karwar institute of medical sciences, Karwar, Ethical committee.

\section{Conflict of Interest: Nil}

\section{References}

1. Brown G, Atkins M, Effective teaching in higher education, London UK Routledge 1988.

2. Rajani Shantthakumari Nagothi, Yogananad Reddy Indla et al, "Effective physiology teaching method: from the prerspective of first year medical students." Indian Jr clin Anatomy, Physiology 2016;3(3):336338.

3. Lalit Mohan, Ravi Shankar et al, "students attitude towards the use of audiovisual aids during didactic lectures in pharmacology".Journal of clinical \& diagnostic research. 2010;12(4):3363-3368.

4. Priyadarshni K.S., H.V. Shetty, Reena R. "assessment of different teaching aids \& teaching method for the better perception of Biochemistry by I ${ }^{\text {st }}$ MBBS students." Journal of evolution of medical \& dental sciences." 2012; December 1(6):1159-1165.

5. Chaudry R, Dullo P, Gupta U. . "Attitude of $1^{\text {st }}$ MBBS medical students about two different visual aids in physilologylectures”. Pak Journal Physiology 2009; 5 (2).

6. Thirunavukkarasu J, Latha K, SathishBabu C., Tharani C.B. A study on effectiveness of different teaching methodology in pharmacology for undergraduate students. Asian J. Exp. Biol. Sci. 2011;2 (3): 487-492.

7. Baxi S N, Shah C J, Parmar R, Parmar, Tripathi C . "students perception of different teaching aids in a medical college" AJHPE 2009; 1(1): 15-16.

8. Roopakulkarni, Ashwini C A, Bharat Reddy. "Students perception on Lectures in medical education. Anatomica Karnataka, 2011; 5(2): 1-13.

9. Garg A, Rataboli PV, Muchandi K. "Students opinion on the prevailing teaching method in Pharmacology \& changes recommended. Indian Journal of Pharmacology 2004, 36: 3, 155-158.

10. Sujata Biswas, Jharna Mukharji Sail Mondal, Impact of electronic \& non electronic teaching method in medical Physiology Indian Medical Gazette- Dec 2013.

Source of Funding: Self 